\title{
Profuse watery diarrhoea: an unusual presenting feature of streptococcal toxic shock syndrome
}

\section{Instructive Case}

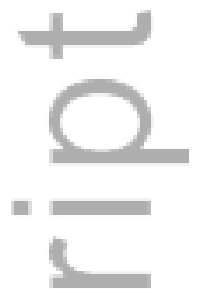

Stephanie Lee, MBBS BMedSci (1)

Julian Kelly, MBBS FRACP $(1,2)$

Pierre R Smeesters, MD PhD $(2,3)$

Andrew C Steer, MBBS BMedSci $(1,2,3)$

\section{Affiliations:}

1. Department of General Medicine, Royal Children's Hospital, Melbourne, Australia

2. Department of Paediatrics, University of Melbourne, Melbourne, Australia

3. Group A Streptococcal Research Group, Murdoch Childrens Research

Institute, Melbourne, Australia

\section{Address Correspondence to:}

Associate Professor Andrew Steer

Centre for International Child Health, Department of Paediatrics, University of Melbourne.

Royal Children's Hospital, Flemington Road, Parkville, Victoria, Australia

Tel: +613 93455522 Email: andrew.steer@ rch.org.au

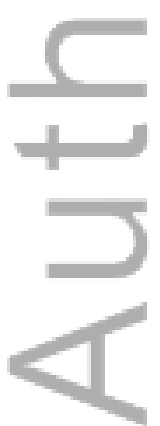

This is the author manuscript accepted for publication and has undergone full peer review but has not been through the copyediting, typesetting, pagination and proofreading process, which may lead to differences between this version and the Version of Record. Please cite this article as doi: 


\section{KEY WORDS}

Streptococcus, toxic shock syndrome, diarrhoea, gastrointestinal, sepsis

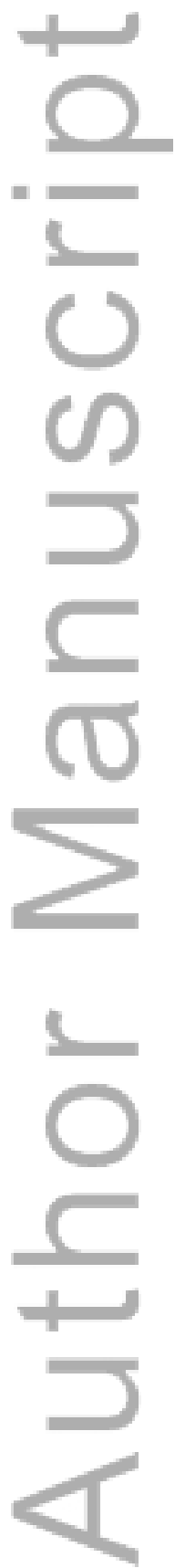

This article is protected by copyright. All rights reserved. 


\section{INTRODUCTION}

The Lancefield group A $\beta$-hemolytic Streptococcus (GAS), also known as Streptococcus pyogenes, causes a spectrum of disease syndromes with varying clinical severity. This ranges from pharyngitis and superficial skin infection to invasive infections. In children, invasive infections can be due to soft tissue infection, pneumonia, osteoarticular infection or bacteremia without focus among others, and may be complicated by streptococcal toxic shock syndrome (TSS) in up to one-third of cases. ${ }^{1,8}$ The diagnosis of streptococcal TSS consists of isolation of streptococci from a normally sterile site and hypotension, together with two or more findings of renal or liver dysfunction, coagulopathy, acute respiratory distress syndrome, rash, or soft tissue necrosis. ${ }^{1}$ This occurs as a result of streptoccocal exotoxins acting as superantigens which induce the release of large amounts of inflammatory cytokines, leading to capillary leak and tissue damage. Group C and G streptococci have also been associated with TSS. We report the case of a child with invasive GAS disease whose most striking presenting feature was profuse watery diarrhoea.

\section{CASE}

A four year old boy presented to our hospital with a 24 hour history of acute onset diarrhoea, vomiting and fever. He had more than 12 bouts of watery diarrhoea prior to presentation associated with abdominal pain, with no blood or mucus in the stool. During this time, he had intermittent confusion, developed leg pain and was reluctant to mobilise. He was previously well aside from a history of asthma treated with montelukast, and there was no history of recent travel or sick contacts.

On presentation, his temperature was $38.9^{\circ} \mathrm{C}$, heart rate 150 beats per minute, respiratory rate 36 breaths per minute, blood pressure 75/41 $\mathrm{mmHg}$ with a capillary refill time of three seconds and cool peripheries. He appeared unwell and was intermittently confused, being unable to answer simple age-appropriate questions. $\mathrm{He}$ had an erythematous, blanching, maculopapular, poorly demarcated rash on his trunk and all four limbs (Figure 1). He had enlarged fungiform papillae on his tongue (Figure 2) consistent with the appearance of strawberry tongue. Abdominal 
examination revealed generalised tenderness but no guarding, and cardiovascular, respiratory and neurological examinations were normal.

His full blood examination revealed a marked leucocytosis of $55 \times 10^{9} / \mathrm{L}$ and neutrophilia of $39 \times 10^{9} / \mathrm{L}$, with haemoglobin $123 \mathrm{~g} / \mathrm{L}$ and platelets $303 \times 10^{9} / \mathrm{L}$. He had an elevated CRP of $255 \mathrm{mg} / \mathrm{L}$ and ESR $70 \mathrm{~mm} / \mathrm{h}$. He had evidence of renal impairment with serum creatinine of $99 \mathrm{umol} / \mathrm{L}$ and urea $16.5 \mathrm{mmol} / \mathrm{L}$. His serum sodium was $130 \mathrm{mmol} / \mathrm{L}$, and potassium $3.3 \mathrm{mmol} / \mathrm{L}$. His liver enzymes were normal. A lumbar puncture was performed which revealed normal cerebrospinal fluid parameters.

The initial differential diagnoses were severe gastroenteritis leading to dehydration with hyponatremia and acute renal failure, acute abdomen, a food hypersensitivity reaction or bacterial sepsis because of the presence of the rash.

After an initial fluid bolus of $20 \mathrm{ml} / \mathrm{kg}$ normal saline his tachycardia and blood pressure improved, and he subsequently commenced intravenous fluids at a maintenance rate. He was commenced on intravenous flucloxacillin and ceftriaxone as per our hospital guidelines for possible bacterial sepsis. The surgical team was consulted. An abdominal ultrasound revealed no abdominal free fluid or collection. After $\mathbf{3 0}$ hours of incubation, $S$. pyogenes (subsequently identified as emm type 4) was isolated from his initial blood culture. Stool cultures were negative, with no leucocytes or erythrocytes on microscopy. His antibiotics were changed to intravenous benzylpenicillin and clindamycin.

Over the course of his five day admission his sodium and creatinine normalised. His bowel actions decreased and he was soon able to mobilise. He was discharged home on oral penicillin $\mathrm{V}$ to complete 10 days of treatment. His immediate family members were prescribed chemoprophlylaxis for invasive GAS disease. His rash had resolved by time of discharge and five days later he developed desquamation of hands and feet.

\section{DISCUSSION}

This article is protected by copyright. All rights reserved. 
The child in our report had streptococcal TSS demonstrated by isolation of $S$. pyogenes from a sterile site, the clinical findings of fever, shock and rash with desquamation and a strawberry tongue, along with evidence of end organ dysfunction (renal impairment). ${ }^{1}$

While profuse diarrhoea forms part of the published diagnostic criteria for staphylococcal $\mathrm{TSS}^{2}$, where the toxins responsible for the disease are able to act as direct enterotoxins, ${ }^{3}$ diarrhoea is not a widely recognised feature of strêptococcal TSS. However, it has been reported that gastrointestinal symptoms may feature in $41 \%$ of children with streptococcal TSS. ${ }^{4}$ Patients with sepsis from any cause, including $S$. pyogenes, may present with gastrointestinal symptoms, but rarely as the presenting complaint and not to the degree as noted in this patient. ${ }^{5,6}$ Patients with primary peritonitis caused by $S$. pyogenes may present with fever and diarrhoea, but they also have prominent abdominal pain. ${ }^{7}$

The mechanism by which $S$. pyogenes led to such profuse diarrhoea in our patient is not clear, but it may have been due to the intense T-cell proliferation and cytokine release that is initiated when streptococcal protein exotoxins acts as superantigens. ${ }^{8}$ These streptococcal superantigens were likely responsible for the rash and strawberry tongue that were observed in our patient.

This case report highlights that streptococcal TSS can present primarily with gastrointestinal symptoms. Gram positive sepsis should be considered in the differential diagnosis of an unwell child with watery diarrhoea and fever, particularly as infection with $S$. pyogenes can rapidly progress to septic shock and multi-organ failure. 


\section{KEY POINTS}

- Streptococcal toxic shock syndrome is characterised by fever and rash with progression to shock and multi-organ failure.

- Streptococcal exotoxins act as superantigens, inducing the release of inflammatory cytokines which lead to capillary leak and tissue damage.

- Although unusual, Streptococcal toxic shock syndrome can present with predominantly gastrointestinal symptoms, including profuse diarrhoea.

a

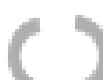

$\infty$

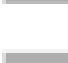

Cos
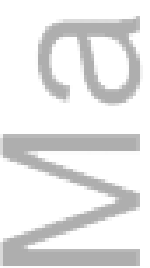

1

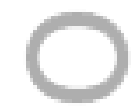

C

I

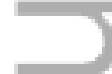

12

This article is protected by copyright. All rights reserved. 


\section{MULTIPLE CHOICE QUESTIONS}

1. The diagnostic criteria for streptococcal toxic shock syndrome (TSS) include all of the following except?

A. Renal impairment

B. Hypotension

C. Diarrhoea

D. Coagulopathy

E. Rash

\section{Answer: C}

The diagnostic criteria for streptococcal TSS includes isolation of GAS from a normally sterile site, hypotension (systolic blood pressure less than the fifth percentile by age), multi-organ involvement characterized by two or more of renal impairment, coagulopathy, liver involvement, acute respiratory distress syndrome, rash (generalized erythematous macular rash that may desquamate) and soft tissue necrosis. Diarrhoea is an unusual presenting symptom of streptococcal TSS.

2. Which other gram positive cocci can cause toxic shock syndrome?
A. Enterococci
B. Streptococcus pneumoniae
C. Streptococcus dysglactiae var equisimilis (Group C and G Streptococci)
D. Viridans Streptococci
E. Staphylococcus aureus

\section{Answer C, D, E}

Although streptococcal TSS occurs most frequently in the setting of infection due to GAS, group C and G streptococci have also been associated with TSS.

Staphylococcus aureus can also cause TSS, although the case fatality rate is reportedly lower than streptococcal TSS.

3. Which antibiotics are recommended for treating streptococcal toxic shock syndrome?

A. Benzylpenicillin and clindamycin 
B. Benzylpenicillin and vancomycin

C. Flucloxacillin and ceftriaxone

D. Ceftriaxone and vancomycin

E. Flucloxacillin and clindamycin

\section{Answer A}

The first line treatment for invasive GAS infection is intravenous benzylpenicillin, which is a cell wall active antibiotic. Clindamycin should be added initially until the patient becomes stable; clindamycin has the theoretical advantage of acting on toxin production.

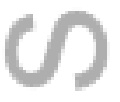

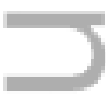
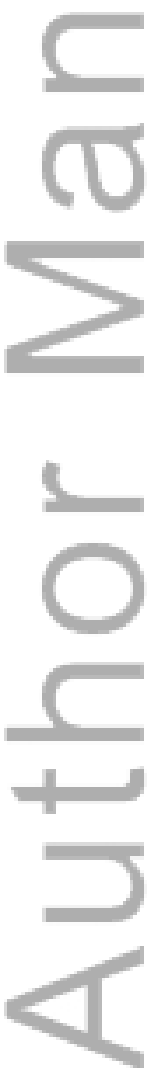

This article is protected by copyright. All rights reserved. 


\section{ACKNOWLEDGEMENTS}

Informed consent: Informed consent was obtained from all individual participants included in the study.

Funding source: No funding was secured for this study.

Financial Disclosure: The authors have no financial relationships relevant to this article to disclose.

Conflict of interest: The authors declare that they have no conflict of interest

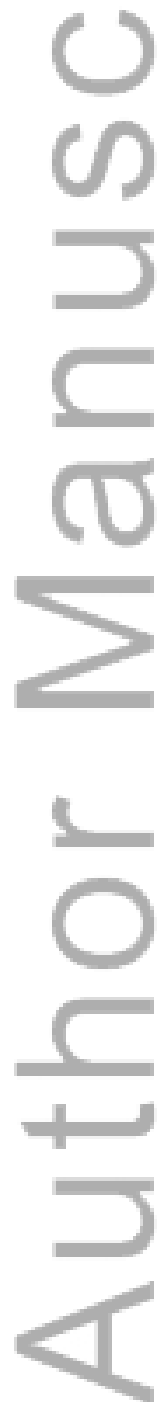

This article is protected by copyright. All rights reserved. 


\section{REFERENCES}

1. The Working Group on Severe Streptococcal Infections. Defining the group A streptococcal toxic shock syndrome. Rationale and consensus definition. JAMA 1993;269:390-391.

2. Reingold AL, Hargrett NT, Shands KN, et al. Toxic shock syndrome surveillance in the United States, 1980 to 1981. Ann Intern Med 1982;96:875-880.

3. 'Kotb M. Bacterial pyrogenic exotoxins as superantigens. Clin Microbiol Rev 1995;8:411-426.

4. Rodríguez-Nuñez A, Dosil-Gallardo S, Jordan I. Clinical characteristics of children with group A streptococcal toxic shock syndrome admitted to pediatric intensive care units. Eur J Pediatr 2011;170:639-644.

5. Hoge CW, Schwartz B, Talkington DF, Breiman RF, MacNeil EM, Englender SJ. The changing epidemiology of invasive streptococcal infections and the emergence of streptococcal toxic shock-like syndrome: a retrospective population based study. JAMA 1993; 269:384-389.

6. Ekelund K, Lemcke A, Konradsen HB. Evaluation of gastrointestinal symptoms as a primary sign of severe invasive group A streptococcal infections. Indian J Med Res 2004;119:179-182.

7. Tilanus AMR, de Geus HRH, Rijnders BJA, Dwarkasing RS, van der Hovern B, Bakker J. Severe group A streptococcal toxic shock syndrome presenting as primary peritonitis: a case report and brief review of the literature. Int J Infect Dis 2010;14; 208-212.

8. Stevens DL, Tanner MH, Winship J, Swarts R, Ries KM, Schlievert PM, Kaplan

-E. Severe group A streptococcal infections associated with a toxic shock-like syndrome and scarlet fever toxin A. N Engl J Med 1989;321(1):1.

This article is protected by copyright. All rights reserved. 


\section{FIGURE LEGENDS}

Fig. 1 Characteristic erythematous, maculopapular, poorly demarcated rash of streptococcal toxic shock syndrome

Fig. 2 Fungiform papillae consistent with the appearance of strawberry tongue

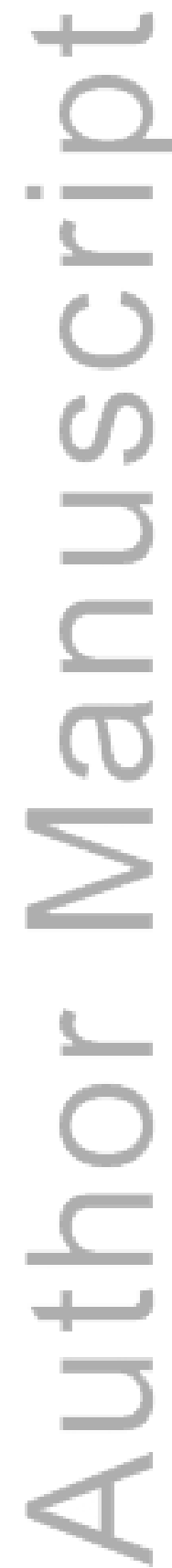

This article is protected by copyright. All rights reserved. 

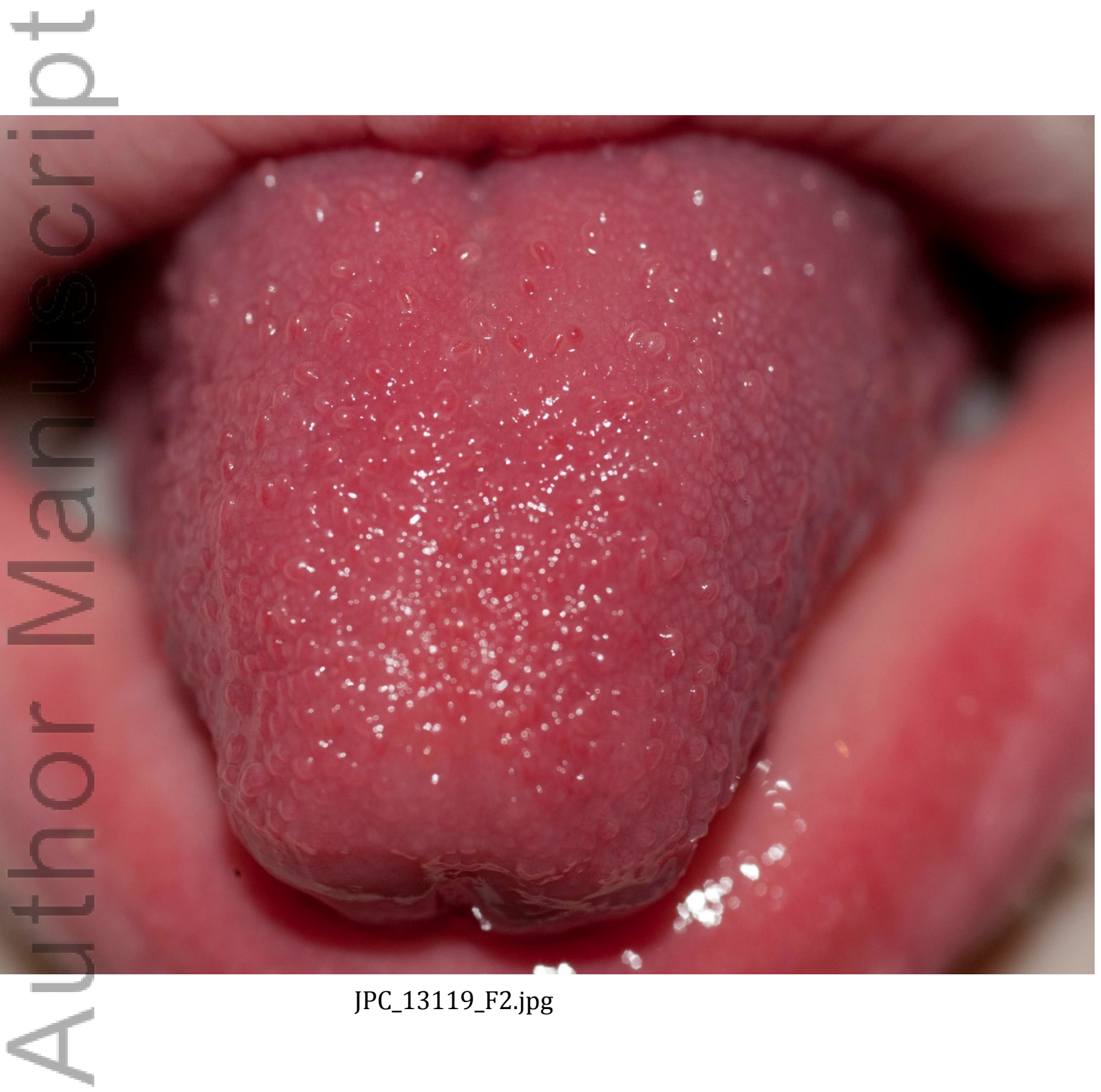

JPC_13119_F2.jpg

This article is protected by copyright. All rights reserved. 


\section{University Library}

\section{- M M N E R VA A gateway to Melbourne's research publications}

Minerva Access is the Institutional Repository of The University of Melbourne

Author/s:

Lee, S;Kelly, J;Smeesters, PR;Steer, AC

Title:

Profuse watery diarrhoea: An unusual presenting feature of streptococcal toxic shock syndrome

Date:

2016-03-01

\section{Citation:}

Lee, S., Kelly, J., Smeesters, P. R. \& Steer, A. C. (2016). Profuse watery diarrhoea:

An unusual presenting feature of streptococcal toxic shock syndrome. JOURNAL OF

PAEDIATRICS AND CHILD HEALTH, 52 (3), pp.342-344. https://doi.org/10.1111/jpc.13119.

Persistent Link:

http://hdl.handle.net/11343/291006 